\title{
Penyuluhan dan Pelatihan Budidaya Jamur Tiram secara Terpadu
}

\author{
Integrated Extension and Training of Oyster Mushroom Cultivation
}

\author{
Khusnul $^{1 *}$, Lusi Nurdianti ${ }^{2}$, Aris Priyanto ${ }^{3}$ \\ ${ }^{1}$ Program Studi D-III Analis Kesehatan STIKes Bakti Tunas Husada Tasikmalaya \\ ${ }^{2}$ Program Studi S-1 Farmasi STIKes Bakti Tunas Husada Tasikmalaya \\ 3 Mitra Petani Jamur "Syahid Mushroom" \\ *khusnul@stikes-bth.ac.id
}

\begin{abstract}
ABSTRAK
Pengembangan budidaya jamur akan terus memberikan sumbangan bagi pembangunan nasional, baik secara langsung maupun tidak langsung. Beberapa alasan yang mendasari pentingnya budidaya jamur di Indonesia antara lain adalah potensi sumber daya alamnya yang besar dan beragam, besarnya penduduk yang menggantungkan hidupnya pada sektor ini dan budidaya jamur menjadi basis pertumbuhan di pedesaan. Tasikmalaya memiliki iklim tropis, dengan curah hujan yang signifikan dan suhu rata-rata $25.2{ }^{\circ} \mathrm{C}$. Hal ini sangat mendukung untuk budidaya jamur tiram. Masyarakat Tasikmalaya belum banyak yang melakukan budidaya jamur, hal ini dikarenakan kurangnya pengetahuan dan keterampilan dalam melalukan budidaya tersebut, petani yang sudah menjalankannyapun masih diperlukan pengetahuan tambahan untuk meningkatkan produksi jamurnya.Tujuan dari penyuluhan dan pelatihan ini adalah untuk memberikan pengetahuan dan keterampilan dalam melakukan budidaya jamur tiram secara terpadu baik untuk petani maupun selain petani. Metode yang digunakan yaitu dengan ceramah dan praktik langsung membuat bibit dan media tanam jamur di laboratorium parasitologi STIKes Bakti Tunas Husada Tasikmalaya. Kegiatan ini diikuti oleh kurang lebih 120 peserta yang berasal dari beberapa daerah di Tasikmalaya maupun di luar Kota Tasikmalaya. Peserta sangat antusias dalam mengikuti kegiatan tersebut.
\end{abstract}

Kata kunci — penyuluhan dan pelatihan, budidaya jamur, petani

\begin{abstract}
The development of mushroom cultivation will continue to contribute to national development, either directly or indirectly. Several reasons that underlie the importance of mushroom cultivation in Indonesia include the potential for large and diverse natural resources, the large number of people who depend on this sector for their lives and mushroom cultivation as the basis for growth in rural areas. Tasikmalaya has a tropical climate, with significant rainfall and an average temperature of $25.2^{\circ} \mathrm{C}$. This is very supportive for the cultivation of oyster mushrooms. There are not many Tasikmalaya people who do mushroom cultivation, this is due to a lack of knowledge and skills in carrying out the cultivation, even farmers who already run it still need additional knowledge to increase their mushroom production. The purpose of this counseling and training is to provide knowledge and skills in mushroom cultivation oysters in an integrated manner both for farmers and non-farmers. The method used is lectures and direct practice of making seeds and mushroom growing media in the parasitology laboratory of STIKes Bakti Tunas Husada Tasikmalaya. This activity was attended by approximately 120 participants from several areas in Tasikmalaya and outside the city of Tasikmalaya. Participants were very enthusiastic in participating in the activity.
\end{abstract}

Keywords - counseling and training, mushroom cultivation, farmers 


\section{Pendahuluan}

Beberapa alasan yang mendasari pentingnya budidaya jamur di Indonesia antara lain adalah potensi sumber daya alamnya yang besar dan beragam, besarnya penduduk yang menggantungkan hidupnya pada sektor ini dan budidaya jamur menjadi basis pertumbuhan di pedesaan. Sumber Daya Manusia Indonesia khususnya yang berkepentingan dalam pembangunan budidaya jamur diharapkan mampu terlibat lebih jauh, diharapkan nantinya kreativitas dan inovasi akan muncul dan mampu memberi nilai tambah bagi Bangsa dan Negara terutama dalam masalah ketahanan pangan.

Pencapaian ketahanan pangan menjadi tolak ukur dari tingkat kesejahteraan suatu bangsa. Dalam sejarah terbukti bahwa tidak ada suatu negara pun yang dapat melaksanakan pembangunan secara mantap sebelum mampu mewujudkan ketahanan pangan. Upaya mewujudkan ketahanan pangan harus bertumpu pada sumber daya pangan lokal dan harus dihindari sejauh mungkin ketergantungan pada impor. Jumlah penduduk dewasa ini mencapai 5,9 milyar orang dan diperkirakan akan terjadi peningkatan jumlah penduduk sebesar 2,0 \% per tahun. Oleh karena itu, perlu suatu usaha peningkatan produksi dari sektor budidaya jamur. Hal ini perlu diperhatikan sehingga nantinya Bangsa Indonesia dapat tercukupi kebutuhan pangannya

Dosen dan Mahasiswa merupakan sumber daya manusia yang diharapkan mampu menjadi pemberi wawasan dan memotivasi kepada tenaga kerja untuk memenuhi kriteria SDM yang berkualitas. Ciri SDM yang berkualitas itu adalah merupakan orang-orang yang terdidik, terampil dan terlatih, mampu menciptakan pengolahan jamur yang kokoh dan mampu mengelola budidaya jamur dengan manajemen dan aplikasi teknologi yang berkembang.

Budidaya jamur mulai mendapat perhatian besar karena jumlah penggemar jamur pangan makin meningkat di dunia. Selain itu, pemanfaatan bahan limbah yang sebelumnya mencemari lingkungan dapat dimanfaatkan untuk pembudidayaan cendawan sampai ke taraf industri. Pembudidayaan jamur, atau di masyarakat lebih dikenal pembudidayaan jamur, semula merupakan suatu bioteknologi tradisional yang sederhana, meliputi tiga kegiatan : 1) pembuatan spawn atau inokulum, 2) pembuatan kompos, yaitu substrat yang akan ditumbuhi jamur, 3) pengaturan lingkungan pertumbuhan agar diperoleh produksi jamur yang maksimal (Indrawati, 2006 [1] ).

Budidaya jamur secara terpadu merupakan salah satu solusi untuk meningkatkan produktivitas hasil panen dengan memperhatikan secara menyeluruh dari setiap tahapan dalam budidaya jamur, baik dalam proses pemilihan isolat murni untuk menentukan kualitas bibit juga hasil panen jamur di medium tanam (baglog). Budidaya jamur yang baik melibatkan beberapa faktor yang perlu mendapat perhatian secara seksama, di antaranya ialah bibit jamur. Meskipun semua faktor dalam kegiatan budidaya jamur telah terpenuhi, tetapi jika bibit jamur yang digunakan kurang baik kualitasnya, maka produksi jamur yang diperoleh tidak akan memuaskan. Faktor dasar yang harus diperhatikan dalam budidaya jamur adalah kualitas bibit, dikarenakan faktor tersebut akan meningkatkan kuantitas dan kualitas hasil panen yang diperoleh (Suriawiria, 1986 [2]), oleh karena itu faktor yang utama dalam budidaya jamur adalah bibit jamur.

Tujuan dari penyuluhan dan pelatihan ini adalah untuk memberikan pengetahuan dan keterampilan dalam melakukan budidaya jamur tiram secara terpadu baik untuk petani maupun selain petani.

\section{Metodologi}

Adapun luaran kegiatan berupa pemahaman dan keterampilan sasaran kegiatan dalam budidaya jamur tiram secara terpadu untuk mahasiswa dan petani jamur. Kegiatan ini dilaksanakan di Aula Graha Husada STIKes Bakti Tunas Husada Tasikmalaya dan di Laboratorium Parasitologi Prodi DIII Analis Kesehatan STIKes Bakti Tunas Husada Tasikmalaya. Waktu penyuluhan dan pelatihan dilaksanakan pada tanggal 2 Juli 2019.

Program kegiatan ini dilaksanakan selama 1 (satu) bulan diawali oleh survei awal dengan mengunjungi Mitra petani jamur tiram di Tasikmalaya yaitu Mitra Syahid Mushroom yang menyediakan bibit jamur untuk petani jamur di Tasikmalaya. Survey dilakukan untuk melihat 
permasalahan-permasalahan yang terjadi dalam pembuatan bibit maupun media tanam jamur.

Kegiatan Pengabdian ini menggunakan pendekatan bersifat persuasif edukatif untuk dengan metode ceramah dan praktik secara langsung. Adapun tahapan kegiatan yang dilakukan adalah sebagai berikut :

a. Persiapan Kegiatan yang dilaksanakan untuk merencanakan kegiatan yang mencakup waktu, materi dan teknis pelaksanaan kegiatan.

b. Konfirmasi dengan pihak STIKes Bakti Tunas Husada sebagai tempat pelaksanaan kegiatan mengenai teknis pelaksanaan, tempat, sarana prasarana dan peserta.

c. Tim Pengabdian dibantu oleh Mahasiswa untuk mengundang masyarakat khusus petani jamurnya untuk menjadi peserta pelatihan dengan target peserta 40 petani jamur dan 80 peserta dari civitas akademika STIKes Bakti Tunas Husada Tasikmalaya.

d. Kegiatan pertama yang dilaksanakan adalah dengan metode ceramah yang digunakan untuk membekali para peserta dengan menumbuhkan motivasi peserta untuk budidaya jamur. Kegiatan ini dilaksanakan di Aula Graha Husada.

e. Metode ceramah digunakan untuk memberikan pengetahuan dan pemahaman tentang karakteristik dan reproduksi jamur tiram.

f. Peserta diajak berdiskusi mengatasi permasalahan-permasalahan dalam budidaya jamur.

g. Setelah pemberian ceramah peserta diajak ke Laboratorium untuk dilaksanakan pelatihan.

h. Pelatihan yang diberikan yaitu teknik pembuatan media agar, teknik kultur murni jamur, dan teknik pembuatan media tanam jamur.

\section{Pembahasan}

Program ini diawali dengan survei kondisi kumbung mitra petani jamur pada bulan Maret 2019. Hasil survei diperoleh kurang optimalnya pertumbuhan jamur baik dari bibit sampai panen, hal tersebut dikarenakan adanya kontaminasi oleh makhluk hidup yang lain Beberapa kemungkinan permasalahan yang menyebabkan terjadinya kontaminasi tersebut adalah faktor pengetahuan dan keterampilan dari petani jamur dalam membuat bibit, medium tanam juga pemeliharaan sampai panen jamur. Maka oleh karena itu perlu adanya penambahan pengetahuan dan keterampilan bagi para petani. Selain itu dilakukan diskusi dengan ketua mitra Syahid Mushroom terkait target utama dalam mengembangkan potensi-potensi masyarakat dalam berbudidaya jamur. Kegiatan survei ini seperti yang tersaji dalam gambar 1 .

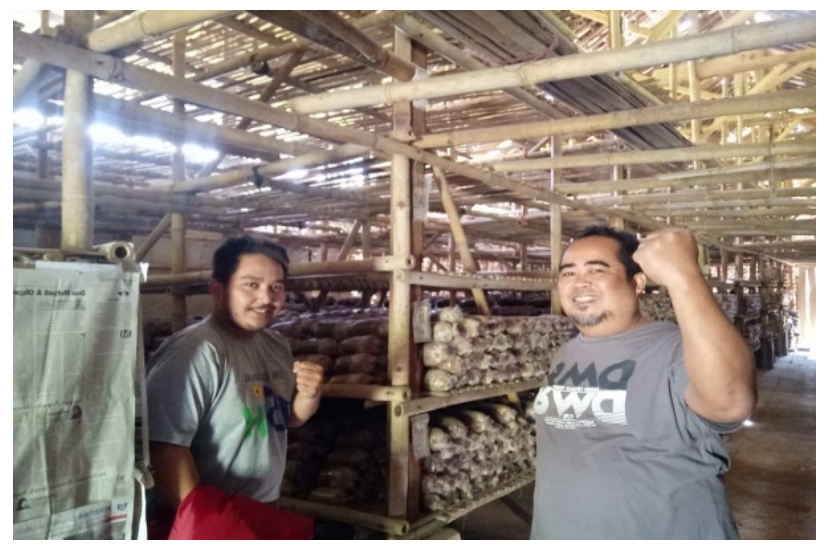

Gambar 1. Foto Kegiatan Survey Permasalahan petani dalam budidaya jamur.

Kegiatan penyuluhan telah diikuti oleh kurang lebih 120 Peserta, dilaksanakan pada Hari Selasa, 2 Juli 2019 bertempat di Aula Graha Husada STIKes Bakti Tunas Husada (BTH) Tasikmalaya Lokasi ini dipilih mengingat sangat strategis dan dapat dijangkau oleh peserta pelatihan serta agar diikuti oleh beberapa civitas akademika STIKes BTH baik oleh mahasiswa ataupun karyawan.

Materi disampaikan dalam bentuk ceramah dengan alat bantu PowerPoint yang disajikan melalui LCD. Materi penyuluhan disampaikan oleh pakar ilmu biologi jamur makroskopis yaitu Dr. Nuniek Ina Ratnaningtyas MS. (Gambar 2). Pada pemaparan materi ini, diarahkan pada pengenalan jamur secara umum dari sifat-sifat jamur, reproduksi, juga kiat-kiat dalam melakukan budidaya jamur, serta proses panen hingga cara pemasaran jamur.

Antusiasme peserta mulai terlihat pada kegiatan penyuluhan ini di mana peserta merespons dengan positif dengan melontarkan berbagai pertanyaan disela-sela pemaparan materi. Banyak hal menarik yang belum peserta ketahui sebelumnya, terutama yang berkaitan 
dengan teori biologis jamur. Selain petani, peserta juga diikuti oleh mahasiswa prodi DIII analis kesehatan yang telah mengampu mata kuliah mikologi. Hal ini membuka wawasan mahasiswa untuk berwirausaha dibidang jamur.

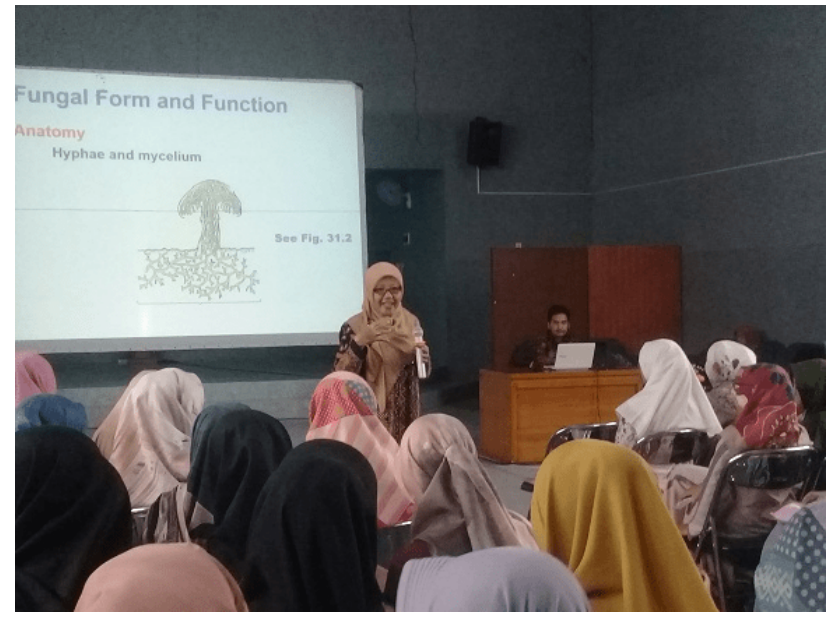

Gambar 2. Foto kegiatan penyuluhan budidaya jamur secara terpadu

Kegiatan selanjutnya dilaksanakan pelatihan yang dilaksanakan di Laboratorium Parasitologi, kegiatan diawali dengan pemaparan hal-hal teknis dalam budidaya jamur, seperti pembuatan media agar, media serealia, teknik inokulasi isolat jamur serta tips dan trik dalam membuat bibit unggul dan berkualitas. Kegiatan tersebut seperti yang tersaji dalam gambar 3 di bawah ini.

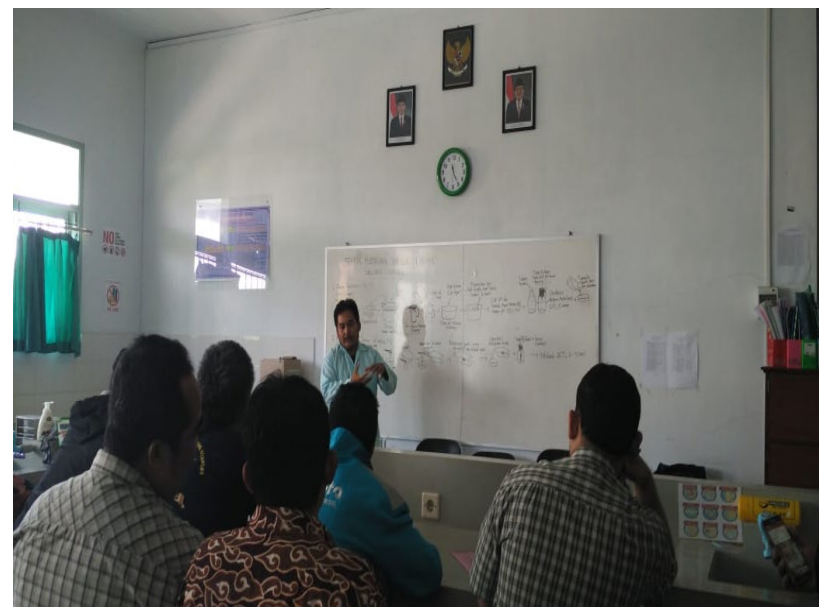

Gambar 3. Foto kegiatan diskusi pembuatan bibit unggul

Kegiatan terakhir dalam pelatihan ini adalah pelatihan membuat media tanam jamur (baglog). Para peserta melakukan pencampuran media tanam yang terdiri dari serbuk kayu, pupuk, kapur dan air secara langsung. Peserta sangat antusias dalam melaksanakan kegiatan ini, masing-masing peserta membuat 3-5 baglog yang kemudian dibawa pulang ke rumah masingmasing untuk diteruskan untuk sterilisasi dan inokulasi bibit jamur. Hal tersebut bertujuan untuk memberikan gambaran proses budidaya jamur bagi petani pemula. Kegiatan tersebut tersaji pada gambar 4 di bawah ini.

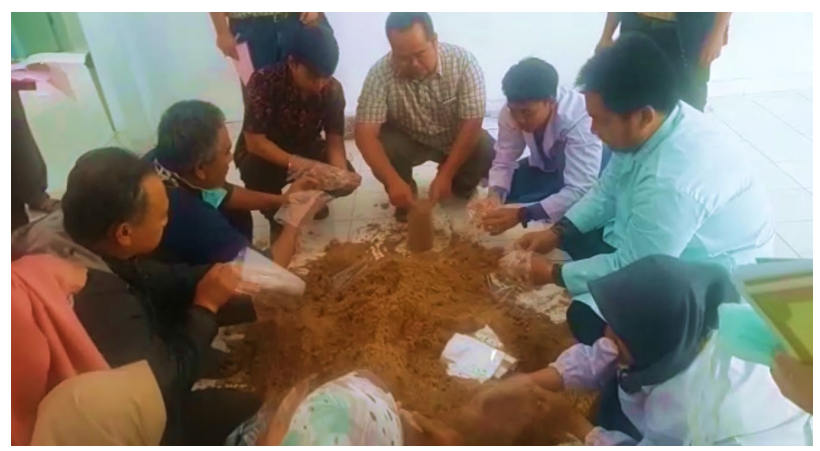

Gambar 4. Foto kegiatan pelatihan membuat media tanam jamur (baglog)

Acara penyuluhan dan pelatihan ini diharapkan semua peserta dapat mengimplentasikannya langsung ditempat masing-masing guna meningkatkan produktifitas jamur yang ada di Tasikmalaya. Setelah kegiatan ini selesei, tim pengabdian melakukan pendampingan secara berkelanjutan untuk lebih meningkatkan keterampilan dan sebagai solusi langsung dalam mengatasi permasalahanpermasalahan budidaya jamur.

\section{Kesimpulan}

Kegiatan ini diikuti oleh lebih dari 120 peserta yang berasal dari beberapa daerah di Tasikmalaya maupun di luar Kota Tasikmalaya. Peserta sangat antusias dalam mengikuti kegiatan tersebut baik saat mengikuti penyuluhan dan pelatihan serta menambah pengetahuan dan keterampilan dalam budidaya jamur.

\section{Ucapan Terima Kasih}

Tim mengucapkan terima kasih yang sebesar-besarnya DITJEN DIKTI / DRPM atas dana yang telah diberikan untuk melaksanakan pengabdian masyarakat Program Kemitraan Masyarakat (PKM) dengan nomor kontrak 
2867/L4/PP/2019 dan kepada STIKes Bakti

Tunas Husada serta Mitra Syahid Mushroom yang telah mendukung dan memfasilitasi kegiatan ini.

\section{Daftar Pustaka}

[1] Gandjar, Indrawati. 2006. Mikologi Dasar dan Terapan. Yayasan Obor Indonesia, Jakarta.

[2] Suriawiria, U. 1986. Pengantar Untuk Mengenal dan Menanam Jamur. Angkasa : Bandung. 